\title{
CORPO, CINEMA E EDUCAÇÃO: CARTOGRAFIAS DO VER
}

\author{
A. A. LIMA NETO ${ }^{1 *}$ e T. P. NÓBREGA ${ }^{2}$ \\ ${ }^{1}$ IFRN. Doutorando em Ciências da Educação - UFRN/Université Paul Valéry. Bolsista CAPES/PDSE. \\ ${ }^{2}$ UFRN. Programa de Pós-Graduação em Educação. Bolsista CAPES de Estágio Sênior - École Normale \\ Supérieure/Paris. \\ avelino.lima@ifrn.edu.br*
}

Artigo submetido em novembro/2014 e aceito em novembro/2014

DOI: $10.15628 /$ holos.2014.2530

\section{RESUMO}

A pesquisa em Educação encontra no cinema um novo campo de exploração investigativa. Ademais, quando o objeto de interesse relaciona-se ao corpo e suas diversas nuances - pedagógicas, culturais, sociais, históricas, filosóficas - tem-se, nas películas, uma possibilidade privilegiada de alargar a experiência do pensamento. No presente trabalho, fundamentando-se na obra do filósofo francês Maurice Merleau-Ponty, partimos do pressuposto de que os estatutos das imagens cinematográficas, no universo da pesquisa, precisam ser vislumbrados de outro modo: não como meras estratégias metodológicas, mas como linguagem indireta que faz o pesquisador ver e pensar de outro modo. 0 presente texto, inspirado nesse pressuposto, configura- se em um percurso assim traçado: o corpo e a visão na filosofia de Merleau-Ponty, que nos permite interrogar o modo como nos dirigimos às imagens e ao mundo da visibilidade, ao visível e ao invisível do que vemos. Essa inspiração primeira nos conduz a nuances epistemológicas e ontológicas que circundam as relações entre o corpo e o cinema. Nosso norte é o texto O cinema e a nova psicologia, cuja leitura impregna nosso olhar sobre o real e o imaginário. Posteriormente, apresentamos um exemplo de como um outro tratamento das imagens é possível. Por fim, à guisa de conclusão, elencamos algumas implicações destas percepções para as investigações no campo da Educação.

PALAVRAS-CHAVE: pesquisa, imagem, cinema, corpo, Educação.

\section{BODY, CINEMA AND EDUCATION: CARTOGRAPHIES OF SEEING}

\begin{abstract}
The research in Education finds in the cinema a new investigative field of exploration. Furthermore, when the object of interest is related to the body in its various nuances - educational, cultural, social historical, philosophical -, we have in films a privileged possibility of extending the experiment of the thought. In this paper, basing on the work of the French philosopher Maurice Merleau-Ponty, we assume that the statutes of the films images in the research domain needs to be envisioned in another way: not as mere methodological strategies, but as indirect language doing the researcher to see and think otherwise. This text, inspired by this assumption, follows the following steps: a reflection on the body and the
\end{abstract}

vision in Merleau-Ponty's thought, which allows us to question how address ourselves to the images and to the world of visibility, to the visible and to the invisible of what we see. This first inspiration leads to epistemological and ontological nuances that surround the relationship between the body and the cinema. Our point of orientation is the text The cinema and the new psychology, whose reading permeates our view of the real and the imaginary. Subsequently, we present an example of how another treatment of the images is possible. Finally in conclusion we list some implications of these perceptions for investigations in the field of Education.

KEYWORDS: research, image, cinema, body, Education. 


\section{CONSIDERAÇÕES INICIAIS}

"O pintor 'emprega seu corpo', diz Valéry."

(MERLEAU-PONTY, 1964, p. 16)

É em Sète, cidade onde nasceu o escritor Paul Valéry, tantas vezes citado por MerleauPonty, que o presente texto tomou forma. Cidade portuária, repleta de canais, nela veem-se navios a chegar e a partir para o Mediterrâneo, visão transformada em poesia pelo seu célebre filho em O cemitério marinho. É deste cemitério que se pode contemplar a paisagem mais privilegiada do mar e da cidade.

Ao descrevê-la em versos, o poeta sétois ${ }^{1}$ cruza a porosidade da existência, em sua materialidade corporal desejada por aquele chão sepulcral, com o poder salgado do mar, "a carne azul". A frescura do vento dele proveniente transubstancia o silêncio da morte em vida: "Corramos à onda para reviver!" (VALÉRY, 2007). E se o próprio Valéry afirma que o pintor emprega o corpo para transformar o mundo em pintura, também o poeta ou o cinema o empregam, transformando o mundo em poesia e em filme, pois nestas expressões, igualmente, o corpo é mistura de visão e movimento (MERLEAU-PONTY, 1964, p. 16). O corpo toca e é tocado pelo que Ihe circunda, transformando a si e a realidade.

Movimentando-nos no cenário educativo, perguntamo-nos se também não seria possível, de algum modo, empregar diferentemente o corpo em nossas práticas de pesquisa, tal qual faz o pintor citado por Paul Valéry. Assim, partimos para a exploração de um dos suportes do visível dos quais Merleau-Ponty lançou mão: o cinema. Sabemos da sua frequente presença nos itinerários de investigação - seja como objeto seja como parte da estratégia metodológica em projetos de pesquisa, dissertações e teses. É fato - e não é recente - que as imagens em movimento ganham espaço no universo educativo e acadêmico.

Cremos, todavia, ser possível experimentar de outros modos a sua potência, potência esta que restringiremos às relações com o corpo - inseparável da visibilidade, como veremos - e com a Educação enquanto campo de investigação. Visa-se, desse modo, oferecer aos pesquisadores algumas pistas teóricas e metodológicas para a realização de uma outra experiência com as imagens, sobretudo as cinematográficas. Evidentemente, não se trata do único modo de tratá-las, mas sim de indicações para um outro modo de ver. Para tanto, baseamo-nos na filosofia de Merleau-Ponty.

Nesse contexto, é importante, desde já, estabelecer um pressuposto fundamental. Seja com Valéry, Proust ou Cézanne; com Hélio Oiticica ou Godard; com Truffaut, Fellini ou com Glauber Rocha, Merleau-Ponty jamais fez uso da arte como um mero instrumento de ilustração ou complemento da teoria, um apêndice do pensamento. Ela é, na verdade, linguagem indireta: possibilita modos outros de ver, pensar, sentir e expressar o mundo. A literatura, a pintura e o cinema foram as operações expressivas por meio das quais o filósofo buscou enfrentar a afasia filosófica de seu tempo, suplantando velhas dicotomias - sujeito/objeto, corpo/mente,

\footnotetext{
${ }^{1}$ Diz-se sétois para a pessoa nascida em Sète.
} 
matéria/espírito, teoria/prática - que, ainda hoje, estão regularmente presentes em nossos itinerários de pesquisa. Propôs, assim, um outro modo de fazer a experiência do pensamento.

O presente texto, inspirado nesse pressuposto, configura-se em um percurso assim traçado: o corpo e a visão na filosofia de Merleau-Ponty, que nos permite interrogar o modo como nos dirigimos às imagens e ao mundo da visibilidade, ao visível e ao invisível do que vemos. Essa inspiração primeira nos conduz a nuances epistemológicas e ontológicas que circundam as relações entre o corpo e o cinema. Nosso norte é o texto $O$ cinema e a nova psicologia, cuja leitura impregna nosso olhar sobre o real e o imaginário. Por fim, apresentamos um exemplo de como um outro tratamento das imagens é possível. À guisa de conclusão, elencamos algumas implicações destas percepções para as investigações no campo da Educação.

\section{2 “PARA COMPREENDER, NÃO É PRECISO DEFINIR, MAS VER" OU, NUMA PALAVRA, SENTIR.}

Como diz o guardador de rebanhos de Fernando Pessoa, "pensar é estar doente dos olhos" (PESSOA, 1997), em uma clara alusão ao racionalismo que bloqueia as vias do pensamento estético do cinema, da literatura, da vida e da existência. "Porque não sabemos o que pensamos", é preciso reconsiderar o modo de fazer filosofia, diz Merleau-Ponty no curso A ontologia cartesiana e a ontologia hoje, proferido em 1960-1961 no Collège de France. Para pensar o hoje - e o que nós somos neste hoje - faz-se necessário desembaraçar-se de uma filosofia presa ao passado, que era muito mais história da filosofia que exercício filosófico em si.

As lacunas desse pensamento, ao invés de assustarem, servem de espaço para um novo pensamento habitar. É justamente aí, tacitamente, que nascem modos outros de compreensão que, na verdade, conforme evoca a citação que abre esta subseção, são novas formas de ver ou sentir. A ontologia que o filósofo propõe para o hoje é, assim, uma ontologia sensível, pois está fundada no corpo, que é capaz de ver e de mover-se (MERLEAU-PONTY, 1996, p. 163-173). Nessa filosofia, o corpo, o esquema corporal por meio do qual existimos, se faz tema primeiro e nos convoca a uma cartografia sensível em todas as suas nuances expressivas.

Toda a obra de Merleau-Ponty está relacionada à necessidade de experimentar o mundo de outro modo, através da reabilitação ontológica e epistemológica do corpo e de sua sensibilidade (NÓBREGA, 2000, p. 97). Desde a Fenomenologia da Percepção (1945), delineiam-se os traços dessa outra maneira de viver o mundo - ou, ao invés, desse esforço de reaprender a vê-lo (MERLEAU-PONTY, 1996, p. 68; 2011, p. 19). A partir de então, o autor aprofunda uma crítica à noção clássica de sensação difundida pelo objetivismo presente no empirismo e no intelectualismo².

Segundo o filósofo, é preciso compreender tal noção não como uma correspondência linear entre o estímulo e resposta, que a física e a biologia bem poderiam descrever. O sentir não é um estado, uma qualidade, uma consciência de estado ou qualidade. Não se trata nem de uma

\footnotetext{
2 Tal interesse de pesquisa já se fazia presente há vários anos no pensamento do autor, como nos demonstram os textos Projeto de trabalho sobre a natureza da percepção, de 1933, e A natureza da percepção, em 1934. Em $A$ Estrutura do Comportamento (1942), com a análise das estruturas neurofisiológicas da percepção, essas questões foram ainda mais aprofundadas, chegando à Fenomenologia da Percepção com certa maturidade - embora não desprovidas de problemas que o filósofo só começou a resolver em suas últimas obras, com uma aproximação cada vez mais intensa com a arte. Cf. MERLEAU-PONTY, Maurice. Le primat de la perception. Lagrasse: Éditions Verdier, 2014 ; __ _ A Estrutura do Comportamento. São Paulo: Martins Fontes, 2006.
} 
recepção passiva do objeto pelo sujeito, nem de um poder absoluto da percepção do sujeito em relação ao objeto. Tanto em um quanto em outro caso - empirismo e intelectualismo -, compreendia-se o sujeito como um espírito desencarnado, que assiste à distância ao espetáculo do mundo (JAY, 1993, p. 165).

A fenomenologia de Merleau-Ponty, diferentemente, propõe pensar a sensação a partir de sua inserção numa determinada conduta, manifesta por meio de olhares, movimentos, gestualidades. Os objetos do mundo - os sensíveis - oferecem uma espécie de problema a ser resolvido pelo sujeito da percepção. É graças ao olhar e à motricidade - isto é, à uma atitude corporal - que a resolução desse problema é viabilizada (MERLEAU-PONTY, 2011, p. 279-289). Em Merleau-Ponty, "os movimentos acompanham nosso acordo perceptivo com o mundo. Situamonos nas coisas dispostos a habitá-las com todo nosso ser. As sensações aparecem associadas a movimentos e cada objeto convida à realização de um gesto" (NÓBREGA, 2008, p. 142).

Explorando a relação entre corpo, percepção e conhecimento em Merleau-Ponty, Nóbrega nos lembra que, a partir de sua incursão na fenomenologia, o autor redimensiona a compreensão tradicional sobre tal tríade. Os processos sensório-motores e a circularidade aí presentes, por meio do fenômeno da sinergia, revelam um novo dado: "Não é o sujeito epistemológico que efetua a síntese, é o corpo; quando sai de sua dispersão, se ordena, se dirige por todos os meios para um termo único de seu movimento" (MERLEAU-PONTY, 2010, p. 312). Assim, refutando a causalidade da atividade perceptiva, não há mais representação (de algo exterior no interior da consciência), "mas criação, novas possibilidades de interpretação das diferentes situações existenciais" (NÓBREGA, 2008, p. 142), que se dão sempre a partir do corpo-sujeito da percepção.

No entanto, já na Fenomenologia da Percepção, mas também em artigos da época ${ }^{3}$, Merleau-Ponty começa a se afastar da fenomenologia - tanto a de Husserl quanto a de Heidegger - denunciando a sua insuficiência em dar conta do fenômeno perceptivo e elaborando, concomitantemente, a crítica mais pertinente desta escola de pensamento (IMBERT, 2005). Nos anos seguintes, o filósofo desenvolverá de modo inovador as suas teses sobre a atividade perceptiva, encaminhando-se para a literatura, a pintura e o cinema como interlocutores de seu esforço filosófico. A partir de $O$ Olho e o Espírito - texto no qual esse esforço aparece emblematicamente - gostaríamos de apontar algumas indicações de caminhos para ver e compreender a realidade diferentemente.

No referido escrito, Merleau-Ponty faz uma crítica ao modus operandi da ciência, bem como de uma filosofia da ciência: a fixação do pensamento num conjunto de técnicas que permitem captar a realidade, para submetê-la ao controle experimental, como num laboratório. Aí, tem-se tão somente um pensamento operatório, uma ciência desencarnada, que sobrevoa o mundo. 0 filósofo, em contrapartida, propõe uma espécie de conversão do pensamento científico através do corpo, a fim de que a ciência deixe de ser "pensamento de sobrevoo".

A pintura é, sem dúvida, uma maneira pela qual podemos deixar de sobrevoar o mundo para poder habitá-lo. Liberado das responsabilidades do homem que fala - isto é, da linguagem que nos posiciona na rígida estrutura de tipo sujeito (pensador) versus objeto (mundo), como acontece com o escritor e o filósofo - o pintor revela um outro modo de experimentar a realidade (MERLEAU-PONTY, 1964, p. 13-14). Esta perspectiva associa diretamente o corpo ao olhar.

\footnotetext{
${ }^{3}$ Referimo-nos, aqui, ao ensaio O filósofo e a sua sombra, publicado em Signos.
} 
O pintor está livre do peso de uma determinada compreensão da linguagem porque pode olhar para o mundo sem se prender à lógica da captura do objeto pelo sujeito falante. Aí, quem fala está sempre atado às ilusórias linearidades entre signo, significado e significante, como se o sentido e a palavra estivessem vinculados por uma correspondência "ponto por ponto" (MERLEAUPONTY, 2004, p. 72). O pintor, ao invés, é "o único a ter direito de olhar sobre todas as coisas sem nenhum dever de apreciação" (MERLEAU-PONTY, 1964, p. 14). Sua técnica é bem outra: está em suas mãos e em seus olhos, que o situam, pela pincelada, na "lógica alusiva do mundo percebido" (MERLEAU-PONTY, 2004, p. 87).

É daí, do toque, do olhar, da visão em movimento que nasce uma ciência secreta, na qual o corpo se posta silenciosamente entre as palavras e as ações do cotidiano. Tal ciência, armada das técnicas da mão e do olhar do pintor, desliza entre os mapas do visível - daquilo que figura diante do meu olhar - e do movimento - isto é, os deslocamentos que, graças ao alcance do olhar, eu posso realizar. Juntos, movimento e visão, efetivados no corpo, facultam-me aproximar-me de todas as coisas do mundo, a olhá-las, senti-las, mas não a me apropriar delas (MERLEAU-PONTY, 1964, p. 14-19).

A capacidade de realizar esse movimento, entretanto, passa por um exercício. O pintor treina o seu olhar, e ele o faz senão ao olhar o mundo. Não há fórmula mágica: ver se aprende vendo (MERLEAU-PONTY, 1964, p. 25). As imagens nos interpelam, nos desestabilizam, nos perturbam com o ataque dirigido ao olhar. Fazendo-o, elas "dão a ver, e ao mesmo tempo dizem algo sobre o que significa ver, nos convidam a uma aprendizagem no sentido pelos sentidos" (PELLEJERO, 2013, p. 309). Assim, para aprender a ver, não há melhor professor e melhor método do que deixar-se atingir pelas imagens.

Talvez, em nossa tentativa de exercitar o olhar, poderíamos nos perguntar: nesta tela, qual foi o emblema da maneira de habitar o mundo que o autor tentou pintar? Que modo de tratá-lo, de interpretá-lo? Como ele coloca aí o seu sentir? O laboratório do pintor é o mundo. Ele pinta as relações com o Ser que se estabelecem no seu cotidiano, nas quais ele mesmo está imerso (MERLEAY-PONTY, 2004, p. 82-84). Esse Ser que é marcado por aquela porosidade evocada por Valéry em $O$ Cemitério Marinho: uma mistura do mundo e de nós mesmos, das coisas e do nosso corpo, que escapa às capturas totais, às objetivações absolutas, à sintaxe da gramática, que é Ser de promiscuidade, porque é carne. Não a carne matéria, mas a carne numa compreensão muito mais próxima da ideia de physis dos antigos: um elemento disperso encarnado em todas as coisas (MERLEAU-PONTY, 2012, p. 136; p. 141; p. 143). Por isso, a nossa carne é feita do mesmo estofo da carne do mundo (MERLEAU-PONTY, 1964, p. 19). A carne dos mortos do cemitério de Sète é a mesma "carne azul" do Mediterrâneo. É este o Ser Selvagem do qual fala Merleau-Ponty. É este o Ser Selvagem que notamos, por exemplo, em Mirco, do filme Vermelho como o céu (2006), quando seu corpo se envolve de tal modo com as coisas ao seu redor que ele se torna capaz de reaprender a ver o mundo - mesmo cego.

O pintor sabe que uma captação completa do mundo ao seu redor é impossível, tanto porque a visão tem seus pontos cegos quanto porque o mundo está sempre em vias de se fazer. Desse modo, o olhar é marcado pela contingência. Por pintar o que vê, o pintor torna a obra acessível aos outros, que partilham com ele a visão; porém, não raro, essa partilha não se efetiva da mesma maneira, haja vista que a imagem desperta outras relações possíveis, pois cada sujeito reage à sua forma ao convite das imagens. $O$ espectador problematiza, ressignifica, redistribui o mapa do visível pelo contato do olho com a imagem, graças às diferentes articulações possíveis no 
amálgama de sua sensibilidade e de seu intelecto. Faz aquilo que, como bem lembra Pellejero, Merleau-Ponty chamou de "deformação coerente" (MERLEAU-PONTY, 2004, p. 85). Se podemos, de algum modo, aprender a ver, isto não se dará senão por essas promiscuidades do olhar que o Ser Selvagem evoca, essas infidelidades do espectador que, somente deformando o que vê, pode criar e, assim, situar-se não na afasia, mas numa operação de expressão, sempre inacabada e prenhe de múltiplos sentidos.

Poderíamos sintetizar essa prática de aprendizagem infiel remetendo-nos às sugestões já doadas por Pellejero (2013, p. 313-316). Para exercitar o olhar, é preciso, primeiramente, dedicar tempo. Não nos deixemos afastar pelo espanto causado por certas imagens. Perseverar nelas obriga-nos a suscitar as diversas capacidades do nosso olhar, entrecruzando-as com os enigmas nascidos desse encontro singular. E, justamente por ser singular, em segundo lugar, o encontro com as imagens também implica uma determinada disposição. Os convites das imagens interpelam a cada um a partir de uma forma específica de organização do próprio desejo, uma posição de afetação, uma disposição do olhar, das reações das respostas negociadas com estes convites. Por fim, o exercício da visão implica também uma questão poética e filosófica, haja vista que, embora nos apoiemos sob suportes conceituais que nos ajudem a experimentar as imagens, eles nunca serão suficientes para traduzir tais experiências, obrigando-nos a criar, na contingência de nossa posição, a ir além do já olhado, pensado ou dito.

Como é notório, diferentemente da ciência, essa ciência do corpo, fundada no enigma da visão e do movimento, experimenta o mundo de outra forma. Recusando-se a apropriar-se da totalidade do significado, Merleau-Ponty lembra-nos que a experiência que o olhar faz com as imagens ata-nos não à necessidade de desvendar o ininteligível, o obscuro ou o escondido localizado supostamente nelas ou por trás delas. É muito mais o processo do pintar que lhe interessa, quando o pintor olha o mundo e vê o que nele falta para ser tela, e vê, também os quadros dos outros e as respostas que eles deram a estas lacunas. É este inventário do visível, inesgotável, denunciando a nossa ignorância e a ingênua inutilidade de uma apreensão total do mundo, o nosso melhor professor (MERLEAU-PONTY, 1964, p. 25-26).

\section{COMO VER? OLHARES A PARTIR DE O CINEMA E A NOVA PSICOLOGIA}

Merleau-Ponty realizou muitos estudos sobre a percepção, seja examinando estados patológicos, como é o caso das sensações do membro fantasma que afetam o esquema corporal, seja examinado os gestos dos pintores modernos como Cézanne, Matisse, Paul Klee, entre outros, para o estudo da percepção das cores ${ }^{4}$ e, sobretudo, do exercício da liberdade na criação artística. Mas, nosso filósofo interessado na percepção e no corpo sensível ao mundo não resistiu ao cinema, pois este nos dá o movimento do corpo. Como veremos, o cinema nos dá a conduta, os comportamentos, as fisionomias que nos abrem um campo de estudo sobre a expressividade do corpo de modo amplo e criativo.

Nesse contexto, somos conscientes de que a complexidade do fenômeno expressivo e a selvageria do olhar não nos permite traçar fórmulas que Ihe aprisionem. No entanto, baseando-

\footnotetext{
${ }^{4}$ O vermelho, por exemplo, é sempre uma concreção de possíveis, é uma pontuação no campo das coisas vermelhas. Assim, há o vermelho das vestes dos professores, do manto dos bispos, das telhas, dos promotores públicos, o vermelho da revolução de 1917, o vermelho do eterno feminino. Um “certo vermelho também é um fóssil retirado do fundo de mundos imaginários", afirmará o filósofo em O visível e o invisível (Merleau-Ponty, 2012, p. 129).
} 
nos no texto $O$ cinema e a nova psicologia, escrito por Merleau-Ponty por ocasião de uma conferência no Institut des Hautes Études Cinématographiques, em 13 de março de 19455, aventuramo-nos a assinalar algumas indicações de ordem teórico-metodológicas concernentes ao trabalho com imagens do cinema.

Nessa ocasião, o autor estabelece, primeiramente, as diferenças entre a Psicologia Clássica e a nova Psicologia, a partir de certas relações que estabelecemos com o mundo e com os outros; em seguida, ele recorre ao exemplo do cinema para demonstrar como atua, de fato, a nova psicologia. Tanto o cinema quanto o pensamento de Merleau-Ponty tomam a experiência perceptiva do mundo como uma de suas preocupações nodais (CHATEAU, 2010, p. 96). É neste suporte artístico que o filósofo encontra uma experiência privilegiada daquilo que mais caracteriza a expressão: a articulação entre movimento e visão ${ }^{6}$.

Sublinharemos, nas linhas seguintes, alguns aspectos que podem auxiliar o pesquisador a estabelecer uma outra relação com as imagens que ele pretende analisar. Trata-se, aqui, de guias na organização do seu olhar com análise de filmes.

\subsection{Ver o conjunto}

Na perspectiva merleau-pontyana, é o conjunto da imagem enquanto tal que deve ser vislumbrado. Os nossos olhos, através da retina, realizam um trabalho de reestabelecimento da homogeneidade do campo visual. Não há um paralelismo entre a sensação e uma determinada excitação nervosa da retina, o que formaria, como que pela montagem de um mosaico ou um quebra-cabeça, na visão. O que vemos "não são elementos justapostos, mas conjuntos" ou "sistemas de configurações" (MERLEAU-PONTY, 1966, p. 63). O papel principal do nosso conhecimento sensível, por isso, é dado à percepção, pois é por meio dela que podemos apreender sensivelmente o fenômeno em seu conjunto (CARBONE, 2011, p. 86). O filme, afinal de contas, é um "objeto a perceber" (MERLEAU-PONTY, 1996, p. 68) (itálico nosso).

Assim, não se pode compreender uma cena enquanto soma de vários elementos, como se a percepção se desse por adição de partes, as quais se juntam e nos dão, justamente por juntarse, um significado. Uma imagem cinematográfica é um alinhamento de certas relações do mundo diante de nós, do nosso olhar. Dirigir-se a ela não exigirá uma operação da inteligência com vistas a decifrar o quebra-cabeça supostamente nela presente, com as possíveis relações paralelas, lineares e causais existentes entre eles. Não se trata de fazer um jogo de ligação entre signos e significados, entre sensações e julgamentos. Experimentar a imagem exigirá do pesquisador uma atitude de desprendimento: é preciso deixar que a integridade da cena se organize diante do seu olhar, resistindo à tentação de isolar seus elementos para, depois, somá-los.

\subsection{Perceber com o Ser inteiro}

Todos os sentidos percebem conjuntamente. Merleau-Ponty cita o exemplo dos cegos, que representam as cores por meio de sons. Mirco, ao falar das cores que ele via antes de tornar-se

\footnotetext{
${ }^{5}$ Trata-se do mesmo ano de publicação de A Fenomenologia da Percepção, obra na qual o autor aprofunda-se na reelaboração da noção de percepção, que ele retoma nas linhas iniciais de $O$ cinema e a nova psicologia.

${ }^{6}$ Perceber-se-á que, no texto em tela, há um forte vínculo de Merleau-Ponty com a Gestalt. Nesta teoria psicológica, a percepção é compreendida a partir da noção de conjunto ou campo, refutando o isolamento de elementos na atividade perceptiva ou sensorial.
} 
cego, utiliza um conjunto de sensações para explicá-las: o azul é como andar de bicicleta e sentir o vento bater no seu rosto, ou mesmo como o mar; o marrom é como a casca áspera de uma árvore; o vermelho é como o fogo, ou como o céu no pôr-do-sol. Nota-se que, aí, não são os sentidos separadamente que estão em jogo. Ao contrário, é nítido que "eu percebo de uma maneira indivisa com o meu ser total, [...] eu apreendo uma única maneira de existir que fala, ao mesmo tempo, a todos os meus sentidos" (MERLEAU-PONTY, 1966, p. 63).

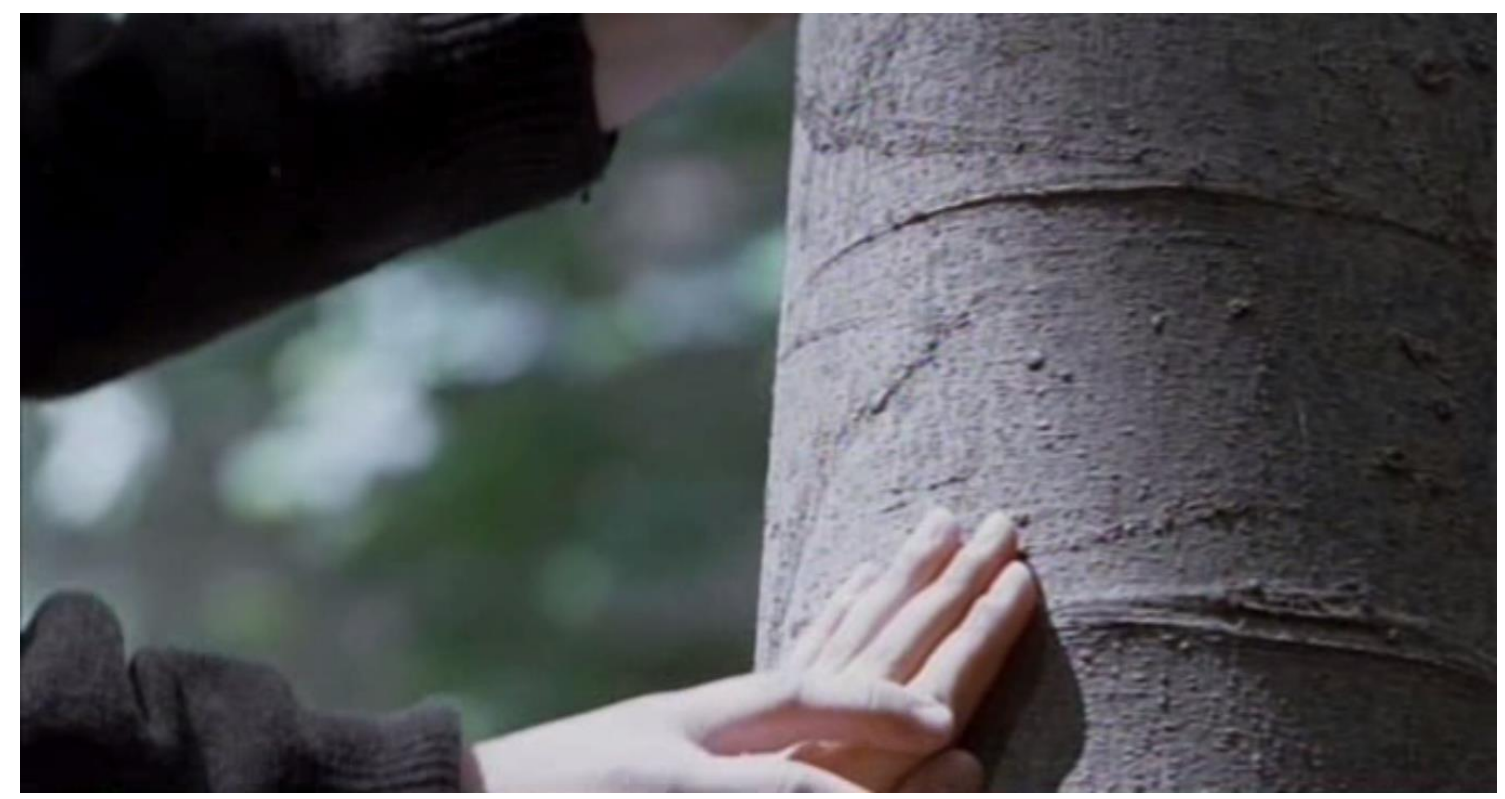

Figura 1: Mirco faz Felice sentir, através do tato, como é a cor marrom.

A atitude do pesquisador não será a de liberar ou interpretar os sentidos escondidos, formando a unidade da percepção por meio de sua inteligência. Seu esforço será o de, dirigindose à imagem, perceber que a tendência de todos os seus objetos é a constância e a estabilidade, que se dá pela configuração do próprio campo visual. Isto quer dizer que "quando eu percebo, eu não penso o mundo; ele se organiza diante de mim" (MERLEAU-PONTY, 1966, p. 65).

Mesmo o movimento está incluso nesta perspectiva. O autor usa dois exemplos muito simples. O primeiro é o do trem. Quando estamos em um trem e, do outro lado, há um outro, pode parecer que os dois estão em movimento ao mesmo tempo, quando, na verdade, só um deles está partindo. Se eu jogo cartas distraidamente, parece-me que o outro trem está saindo; quando olho nos olhos de alguém do outro trem, parece que parte aquele no qual estou. Um outro exemplo: às vezes eu olho o campanário de uma igreja e ele me parece imóvel, com nuvens que voam sobre ele; outras vezes, são as nuvens que parecem imóveis, enquanto o campanário se desloca.

À que conclusão chega Merleau-Ponty? Para ele, quando o olhar se demora sobre um objeto, este lhe parecerá fixo; todavia, se o espectador desvia o olhar, ele perderá este significado. Não se trata, por isso, de uma escolha arbitrária causada por uma operação da inteligência, que escolhe um ponto de referência (MERLEAU-PONTY, 1966, p. 65-66). Perceber com Ser inteiro exigirá do pesquisador, portanto, a consciência de que o campo visual é campo corporal. É a relação do corpo com o mundo, com os seus arredores - aqui representado nos seus sentidos e movimentos - que determinará a atividade perceptiva. 


\subsection{Olhar o corpo}

A Psicologia Clássica fazia uma distinção entre observação interior (introspecção) e observação exterior. Os fatos psíquicos - como os sentimentos de vergonha, medo, cólera e amor por exemplo - só podiam ser analisados a partir da dimensão interior, já que eram compreendidos como pertencentes à psique dos indivíduos, sendo acessíveis somente a eles. Já a nova Psicologia afirma que a observação interior não dava muito a conhecer, posto que nos oferecia somente traços simples dos referidos fatos psíquicos. Era preciso, na verdade, compreendê-los a partir das relações que o indivíduo estabelece com os outros e com o mundo. Como fazê-lo?

Merleau-Ponty dirá que os fatos psíquicos não estão "escondidos no mais profundo da consciência dos outros; são tipos de comportamento ou estilos de conduta visíveis de fora. Eles estão sobre este rosto ou nestes gestos, e não escondidos por trás deles" (MERLEAU-PONTY, 1966, p. 67) (itálico do autor) ${ }^{7}$. A busca pelo sentido dos sentimentos, emoções, afetos, passará, portanto, pelo olhar do pesquisador sobre o corpo: é preciso ler os seus gestos e atitudes. As relações que estabelecemos com o mundo, com os outros e aquelas que os outros estabelecem conosco não são aí apreendidas de modo indireto, como que por um atalho. Quando o filósofo afirma que o sentido está no gesto, dando ênfase à preposição, é porque é no corpo mesmo ele habita, não por superposição, mas pela natureza mesma do corpo. Nesse sentido, o corpo é o meio através do qual o pesquisador da imagem poderá chegar ao significado.

\subsection{Atenção aos tempos e ritmos}

Quando voltamo-nos ao filme enquanto "objeto a perceber", temos de nos lembrar que a percepção dele se dá do mesmo modo que a percepção sustentada pela nova psicologia - isto é, a partir da noção de conjunto - conforme assinalamos anteriormente. Ademais, ainda é preciso atentar para uma outra característica central. Para Merleau-Ponty (1996, p. 69), "o filme não é uma soma de imagens, mas uma forma temporal [...]. O sentido de uma imagem depende, portanto, daquelas que a precedem no filme, e sua sucessão cria uma nova realidade que não é a simples soma dos elementos empregados" (itálico do autor). O filme só será bem analisado, portanto, se considerarmos o seu caráter de forma temporal.

Olhar o filme a partir desta perspectiva nos faz lembrar que ele não pode ser reduzido, simplesmente, a uma sequência de imagens. Estar atento ao tempo exigirá considerar a duração de cada imagem, e essa só poderá ser bem analisada caso seja visualizada a partir de sua inserção no ritmo do filme, isto é, em união com as imagens que a precederam, com seus próprios ritmos, e as que lhe sucederão. Nesse sentido, prestar atenção à montagem enquanto síntese dos vários elementos nos planos filmados é importante. Isso não quer dizer, contudo, que não podemos nos deter sobre uma imagem específica do filme. Na perspectiva assumida, o que seria contraditório é tomar a imagem isoladamente, separando-a do tempo e ritmo. Só enquanto forma temporal o filme pode adquirir sua "expressão original" 8 .

\footnotetext{
${ }^{7}$ Anos depois, em A ciência e a experiência da expressão, Merleau-Ponty dirá: "Não podemos imitar a voz de alguém sem retomar alguma coisa de sua fisionomia e, enfim, de seu estilo pessoal. Assim, a voz do autor termina por induzir, em mim, o seu pensamento" (MERLEAU-PONTY, 1969, p. 19).

8 " [...] a adição de um plano e de um outro plano leva não à adição do sentido do qual eles são portadores, mas a sua multiplicação", afirma o diretor e estudioso do cinema Vincent Pinel (1996, p. 255), corroborando com a postulação de Merleau-Ponty.
} 


\subsection{Diálogos, música, silêncios}

As palavras presentes nos diálogos, a trilha sonora e os ruídos do filme, bem como os silêncios, formam um todo inseparável com a imagem. Esta última é transformada graças aos referidos componentes. As palavras e os silêncios podem promover ou não um maior efeito da imagem. A música, por sua vez, não é um adorno justaposto à cena, mas deve ser a ela incorporada. Não é uma mera representação dos sentimentos ou pensamentos dos personagens, mas um artefato que "torna, enfim, fisicamente sensível o ritmo interno da imagem" (MERLEAU-PONTY, 1996, p. 72).

Quando o pesquisador se detém sobre estes outros componentes da cena - os diálogos, as músicas e os silêncios - não deve se perguntar se eles querem dizer algo que a imagem ainda não disse ou que ela esconde. É preciso centrar-se, por outro lado, no conjunto indiviso da imagem. É ele que "nos diz alguma coisa muito precisa, que não é nem um pensamento nem uma lembrança dos sentimentos da vida" (MERLEAU-PONTY, 1996, p. 72).

Em Vermelho como o céu, quando Mirco vai pela primeira vez ao refeitório (em seu primeiro dia na escola para cegos), os ruídos da cena são compostos pelo alto volume dos talheres que as crianças batem nos pratos, bem como pelo som das cadeiras sendo arrastadas e pelas inúmeras vozes, das quais, devido ao aglomerado de sons, não podemos decifrar uma palavra. Sentimo-nos como o menino que, dando os primeiros passos enquanto cego, sente-se confuso e perturbado pelo turbilhão de sons ao seu redor. O que este conjunto nos diz, ele o faz não porque remete-nos imediatamente às ideias organizadas pela inteligência, mas por dispor temporal e espacialmente os elementos da cena. Os sons, as palavras e os silêncios, inseridos no ritmo, são o "monograma sensível e sonoro" (MERLEAU-PONTY, 1996, p. 73) das ideias e dos fatos do mundo de Mirco.

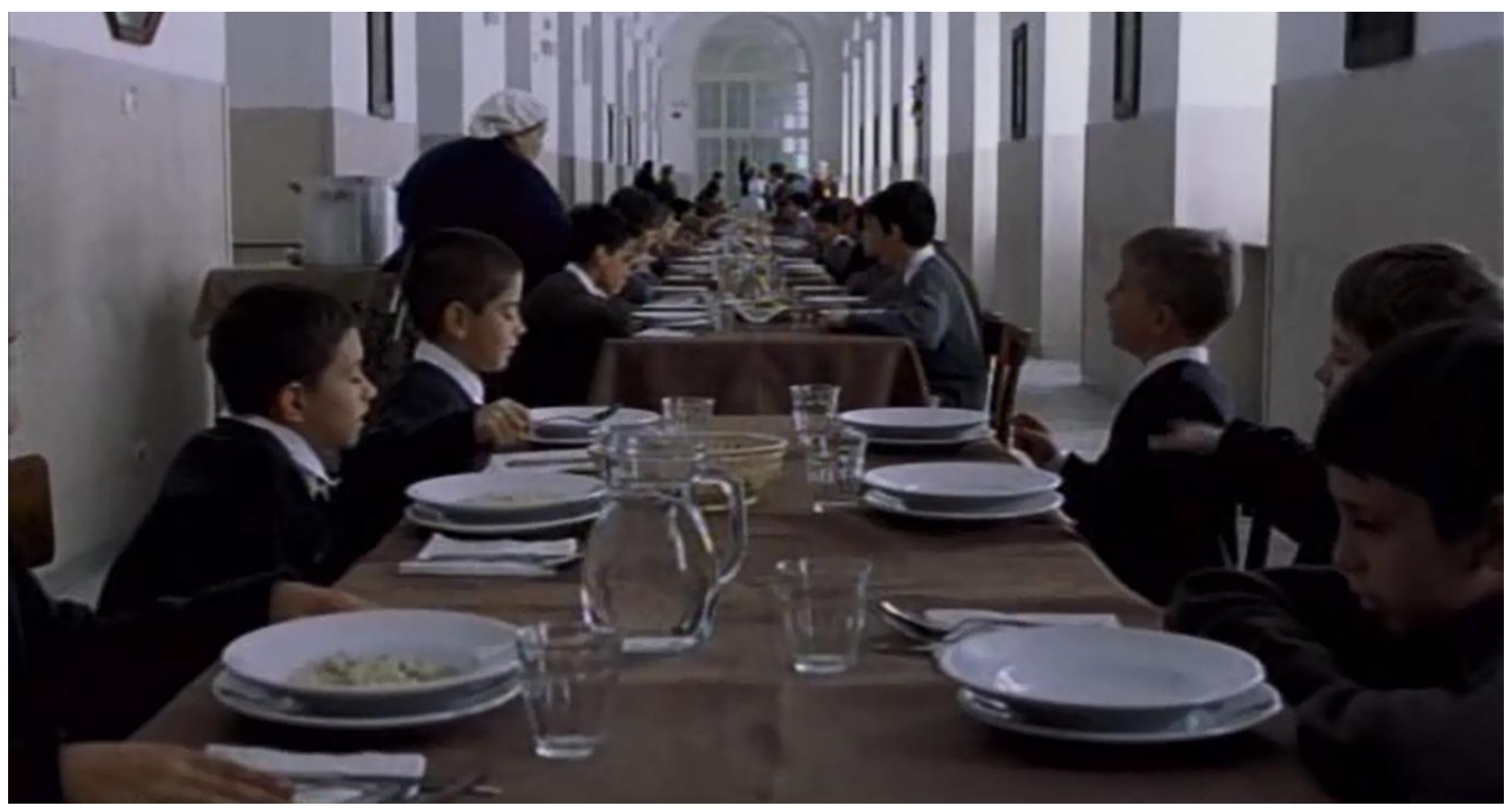

Figura 2: Os muitos sons que tocam Mirco - e ao espectador - no seu primeiro dia na escola.

É por isso que, quando tomamos o homem por objeto de pesquisa, podemos encontrar no cinema um campo de exploração tão privilegiado. Nele, a expressão se torna experiência possível. Com ela, acessamos o campo do visível por meio do corpo: nos gestos, no olhar, nas posturas em 
geral. Assim, as condutas e relações humanas - consigo, com os outros, com o mundo - se nos dão de modo diferenciado. (MERLEAU-PONTY, 1996, p. 74)

Nota-se, portanto, que as imagens cinematográficas amplificam nosso olhar, alteram nossa percepção, nos retiram da paisagem comum para nos permitir ver de outras maneiras, encantados com a magia do cinema e o poder de suas imagens em movimento. Mergulhamos num universo em que histórias são contadas em um tempo e em um espaço dilatados da percepção cotidiana.

As linhas anteriores nos mostraram que a sensibilidade não nos dá uma ideia confusa do mundo - como pensavam os adeptos do pensamento de Descartes ou os cientistas positivistas, dada a relação das sensações com o corpo e com a subjetividade, compreendidos como fontes de erro. A percepção diz respeito a um mundo percebido onde os objetos e os acontecimentos possuem significados variados, conforme os contextos distintos em que ela se desenvolve, como constatamos.

\section{UM EXEMPLO: A PESQUISA VISIBILIDADES DO CORPO E DA CULTURA DE MOVIMENTO URBANA}

Nessa aventura do olhar, trazemos o exemplo da pesquisa Visibilidades do Corpo e da Cultura de Movimento Urbana". Nessa ocasião, objetivou-se produzir, analisar e arquivar "imagens das práticas corporais realizadas nos espaços públicos e privados da cidade, assim como imagens cinematográficas, buscando-se construir uma rede de significados relacionados aos usos e investimentos do corpo e a configuração de uma cultura de movimento urbana" (NÓBREGA, 2011).

A pesquisa, de natureza fenomenológica, combinou a reflexão filosófica com indicadores sociais, fotografias, vídeos, cinema e depoimentos públicos. Como técnica de pesquisa foi utilizada a produção e a análise de imagens relacionadas ao corpo e a cultura de movimento na cidade. Nesse sentido, houve dois principais resultados materiais: a produção do documentário $O$ corpo $e$ a cidade (2011) e a construção de um arquivo com análises de obras cinematográficas. Em ambos, a materialidade do filme e dos corpos se cruzam.

De acordo com Baecque (2009, p. 481), "a própria matéria do filme é o registro de uma construção espacial e de expressões corporais. Registrar com o auxílio de uma câmera, corpos que se relacionam em um espaço, eis a definição dessa organização formal chamada cinema". O cinema nos oferece uma visibilidade para o corpo e sua expressividade, que pode contribuir para perceber o conhecimento sensível da Educação em relação à experiência corpórea, ao esquema corporal, as fisionomias que reúnem comportamento e emoção e ao movimento dos corpos no espaço e no tempo.

Nos filmes, o corpo do cotidiano prolonga-se em corpos extraordinários que nos dão a perceber de modo mais aguçado e assim nos fazem refletir sobre nossa condição corpórea, humana, seja em situações da vida privada seja em situações sociais mais abrangentes. O filme cinematográfico é também um arquivo de corpos e de acontecimentos que nos transporta para realidades e mundos compartilhados pela presença perceptiva, despertando nossas sensações e provocando nossa reflexão sobre temas, acontecimentos, emoções, entre outros aspectos que permeiam a vida e a existência humanas.

\footnotetext{
${ }^{9}$ Pesquisa financiada pelo edital MCT/CNPq № 14/2009 - Universal.
} 
Para tratarmos essas questões, consideramos a arte cinematográfica como estímulo à reflexão para a criação e análise de significados atribuídos às práticas corporais, ampliando assim o modo de compreensão sobre esse fenômeno, por meio do olhar estético sugerido por essa arte. Ao discutir a produção das imagens no cinema, Xavier (1997, p. 367), corroborando as intuições de Merleau-Ponty anteriormente apresentadas, afirma que:

as relações entre o visível e o invisível, a interação entre o dado imediato e sua significação tornam-se mais intricadas. A sucessão de imagens criada pela montagem produz relações novas a todo instante e somos sempre levados a estabelecer ligações propriamente não existentes na tela. A montagem sugere, nós deduzimos. As significações se engendram menos por força de isolamento, mais por força de contextualizações para as quais o cinema possui uma liberdade invejável. (itálico nosso)

Essa dimensão perceptiva da imagem em movimento no cinema propicia novas maneiras de ver o mundo, criando novos regimes de visibilidade e de expressão para o corpo. A arte, assim como a filosofia e a ciência buscam nos retirar de nossas paisagens habituais para nos fazer perceber outras dimensões da vida e dos acontecimentos. Ao considerar esse aspecto estético, a análise de imagens do cinema apresenta-se como possibilidade para se perceber os usos e investimentos do corpo, as fisionomias, o esquema corporal, a gestualidade e outros aspectos relacionados ao movimento e à cultura. O exercício do olhar através da produção e apreciação de imagens contribui para ampliar a percepção sobre a corporeidade.

Conforme Aumont (2007) e Martin (2007), a técnica cinematográfica apresenta elementos tais como: o argumento, o foco narrativo, a trilha sonora e a sonorização, a fotografia e o movimento de câmera. O argumento diz respeito ao sumário da história, motivação dos personagens, enredo. Já o foco narrativo envolve a perspectiva da qual a história é contada (subjetiva - visão personagem ou objetiva quando centrada em fatos exteriores). A trilha sonora e a sonorização englobam a parte musical, efeitos sonoros, ruídos, diálogos ou falas, silêncios, som em off ou real. Já a fotografia diz respeito às cores, tons predominantes, contraste (luz e sombra), efeitos de iluminação (foco, penumbra, etc.). O movimento da câmera envolve o enquadramento e os planos, a animação, efeitos gráficos, trucagem, fusão. Os planos abrangem o plano geral; plano médio (pessoas, objetos); primeiro plano (rosto); americano (do rosto até a cintura), plongée (mergulho), contra-plongée, traveling (panorâmica).

Embora essa apreciação da técnica cinematográfica seja importante, na pesquisa é igualmente relevante colocarmo-nos na condição de espectadores e tomarmos o cinema como educação do corpo, do olhar e da sensibilidade, haja vista que não se trata de uma ação de direção, produção ou mesmo de crítica do cinema, mas de um investigador que se envolve nas dinâmicas da visibilidade suscitadas pela arte em questão.

Adotando este entendimento no que concerne à análise de filmes, a pesquisa Visibilidades do Corpo e da Cultura de Movimento Urbana criou uma ficha para realizá-la (Cf. Tabela 1). Esta se constituiu no esforço de perceber os usos e investimentos do corpo, as fisionomias, o esquema corporal, a gestualidade e outros aspectos relacionados ao movimento, ao corpo, à cultura. 0 exercício do olhar através dela contribuiu para ampliar a percepção sobre o fenômeno investigado e a alcançar o objetivo da pesquisa. 
$\mathrm{Na}$ ficha estão elencados aspectos relativos à técnica cinematográfica e aspectos relativos ao corpo e à cultura de movimento. O item 1 (Sobre a técnica cinematográfica) destaca os aspectos técnicos do filme de modo descritivo. No item 2 (Sobre o corpo e a cultura de movimento), a partir dos indicadores apontados, podem-se construir tópicos interpretativos, intentando responder as questões da pesquisa a partir do referencial teórico adotado - no caso, a fenomenologia de Merleau-Ponty.

Tabela 1: Ficha para análise de filmes (NÓBREGA, 2011)

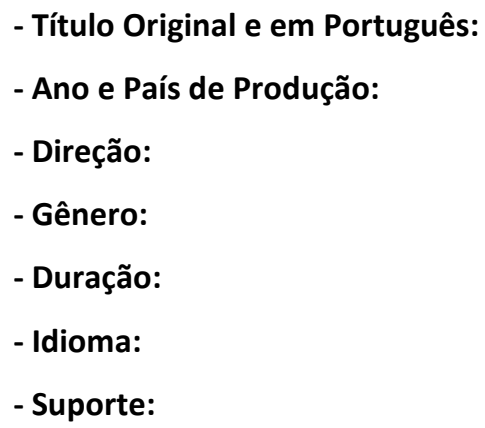

\section{Sobre a técnica cinematográfica}

Argumento - Sumário da história, motivação dos personagens, enredo.

Foco narrativo - Perspectiva da qual a história é contada (subjetiva - visão do personagem; objetiva).

Cenário e Figurino - Natural, estúdio, realidade, figurado.

Trilha sonora/sonorização: parte musical, efeitos sonoros, ruídos, diálogos ou falas, silêncios, som em off ou real.

Fotografia e Câmera - Fotografia - Cores, tons predominantes, contraste (luz e sombra), efeitos de iluminação (foco, penumbra, etc), animação, efeitos gráficos, trucagem, fusão; Enquadramento, Planos - Plano Geral; Plano Médio (pessoas, objetos); Primeiro Plano (Rosto); americano (do rosto até a cintura), plongée, contra-plongée, traveling.

\section{Sobre o corpo e a cultura de movimento}

Corporeidade e Movimento: percepções sobre a corporeidade, a ludicidade, a saúde, a estética, a aparência do corpo; práticas corporais evidenciadas; ideologias do corpo e da saúde; transformações na aparência do corpo; corpo e moda; corpo e biotecnologias.

O corpo e a Cidade: descrição dos meios urbanos, relações entre o espaço do corpo e o espaço urbano

Corpo e tempo: descrição das transformações históricas e sociais relativas ao corpo e a cultura de movimento, ritmos urbanos.

Corpo e Estesia: percepções sensoriais, afetos, emoções, sexualidade, imaginário

Corpo e Instituições: relações com a educação e/ou Escola, família, instituições educativas, científicas e culturais; relações de poder; ideologias

Corpo e ética: aspectos relativos ao bem-viver e ao viver com na cidade, valores morais, questões relacionadas à liberdade, à vida de forma geral e que atingem os sujeitos de forma individual e coletiva.

\section{Palavras-chave:}

Pesquisador: 
Vejamos como, por ocasião da referida pesquisa, foi analisado o filme As bicicletas de Belleville.

Tabela 2: Ficha de Análise do filme As bicicletas de Belleville (NÓBREGA, 2011)

- Título Original e em Português: Les triplettes de Belleville/ As bicicletas de Belleville

- Ano e País de Produção: França/2003

- Direção: Sylvain Chomet

- Gênero: animação

- Duração: 82 minutos

- Idioma: francês

\section{Sobre a técnica cinematográfica}

Argumento - Champion é um menino solitário que reencontra a alegria perdida desde a morte dos pais ao ganhar de sua avó uma bicicleta. Percebendo a aptidão do garoto, sua avó começa a incentivar seu treinamento para fazêlo um verdadeiro campeão e poder participar do Tour de France. Durante a competição, Champion é sequestrado. Sua avó, Madame Souza e seu cachorro Bruno partem em sua busca, chegando a uma megalópole localizada além do oceano, chamada Belleville, e que lembra Nova York.

Foco narrativo - A avó, auxiliada pelo cachorro Bruno, comanda a aventura para salvar o neto da máfia francesa. Toda a aventura é marcada pelo afeto que essa senhora tem pelo neto e o desejo de vê-lo feliz.

Cenário e Figurino - O cenário é criado para lembrar cidades do sul da França como Marseille e Nova York, bem como para nos inserir em uma atmosfera nostálgica que toca nossa alma, que nos diverte, que nos faz sentir a importância da amizade, do afeto.

Trilha sonora/sonorização: a música do acordeom francês é marcante, bem como o jazz. A trilha sonora marca a diferença de ambiente e das ações. A música também realça o quanto de superficial tem algumas atitudes humanas e a necessidade de ouvir as coisas de modo mais atento, sutil, profundamente.

Fotografia e Câmera - Fotografia - Há cenas em preto e branco que marcam a passagem das estações, do tempo. Há cenas coloridas, em amarelo, que remetem ao sol, ao nascer de um novo dia, novas esperanças. $O$ filme apresenta um ritmo lento, mas dinâmico, afinal trata-se de um filme de aventura. No entanto, a aventura é sutil e movida não por efeitos mirabolantes, mas por pequenos gestos que os espectadores admitem apenas por se tratar de uma animação, como por exemplo, a cena em que a avó consegue interceptar um carro em alta velocidade colocando a sua bota ortopédica como barreira.

\section{Sobre o corpo e a cultura de movimento}

Corporeidade e Movimento: é possível perceber a mobilização dos franceses pelo Tour de France, sua paixão pela bicicleta. Destaca-se também o treinamento que a avó empreende para fazer de seu neto um campeão, o que não foi muito difícil, dada a paixão do menino por bicicletas e a lembrança afetiva de seus pais que esse veículo lhe trazia.

O corpo e a Cidade: o ritmo da cidade é marcado pelo movimento dos carros, trens, máquinas. Mas há também o ritmo dos humanos e dos animais que buscam seu lugar na cidade e os rastros de subjetividade que acompanham nosso contato com o mundo.

Corpo e tempo: há o tempo das máquinas, o trem, o relógio, a televisão, que marcam a passagem das horas, a espera de Bruno pelos donos. Há o tempo das pedaladas de Champion pelo tempo da vida, desde sua infância à idade adulta e a velhice diante da TV.

Corpo e Estesia: há uma mistura entre a vida de Bruno e o que se passa em um filme que o menino assiste na televisão, de modo que ficamos em dúvida se ele viveu toda essa aventura ou se foi apenas sua imaginação. No entanto, essa dúvida não é o mais importante e sim a complementaridade, a dobra entre o real e a imaginação que faz se sentir na passagem do tempo em nossas vidas tomadas em perspectiva pela vida de Champion, Madame Souza, Bruno (o cão) e outros personagens geniais como as trigêmeas de Belleville. 
Corpo e Instituições: o esporte como competição, com suas regras e treinamentos e o esporte como experiência humana, como aquilo que dá sentido à vida para uma criança que perdeu os pais e que reencontra em uma bicicleta a energia necessária para sonhar e viver.

Corpo e ética: A atitude da avó de Bruno em sua busca para substituir os pais do menino. Destaca-se também a parceria e a amizade entre madame Souza e três cantoras de cabaré que foram famosas na década de 1930 e que agora vivem em decadência.

3. Palavras-chave: movimento; afetividade; ética; esporte; cultura.

Os elementos elencados no item 2, sendo de natureza específica - pois referem-se à pesquisa em questão -, articulam-se aos indicadores apresentados na subseção anterior, isto é, os guias mais gerais para a organização do olhar do pesquisador. Se este olha a cena com vistas a perceber elementos relacionados às categorias Corpo e Instituições, por exemplo, ele o fará sempre a partir do conjunto, consciente de que percebemos com o Ser inteiro, atento ao poder expressivo do Corpo, aos tempos e ritmos bem como aos sons e ruídos em geral. É assim que se entende, por exemplo, no filme aqui analisado, o esporte como experiência humana ampla, que supera as competições, o que ajudou Bruno a reconfigurar os sentidos da sua vida.

Posteriormente, com o término da pesquisa e o aumento de produções científicas que dialogavam com o cinema, acrescentou-se na ficha um outro item: a análise de cenas. A partir dos indicadores já elencados no item 2, o pesquisador passaria, doravante, a reter o seu olhar sobre imagens ou sequências de imagens específicas, com vistas a melhor explorar as perguntas de sua pesquisa. Evidentemente, o item 2 é variável. Ele se adaptará à problemática, aos objetivos, às questões de pesquisa e ao referencial teórico. Cada pesquisa exige a produção de uma ficha, mostrando que a contingência do olhar atinge, também, a contingência das nossas estratégias metodológicas.

\section{CONSIDERAÇÕES FINAIS}

Feitosa (2004) retoma de Aristóteles uma importante reflexão sobre a arte e sua função de catarse. A catarse é um termo oriundo da medicina e que significa literalmente o processo de purgação dos elementos perniciosos presentes no corpo. Através da arte, o espectador é incentivado a sentir fortes emoções, tais como o medo, a piedade ou o entusiasmo sem cair em descontrole, desespero ou um perigo real. Após a catarse vem o alivio e a sensação de equilíbrio. A catarse contribui para fortalecer na plateia o sentimento de comunidade, uma vez que todos compartilham essas emoções catárticas que agregam razão e afetividade. Trata-se assim também de uma função pedagógica e edificante.

O filme excita, assim, numa pedagogia selvagem, promíscua, que convoca todos os nossos sentidos, tanto uma identificação com o semelhante como uma identificação com o estranho. 0 cinema, como o sonho, como o imaginário, acorda e revela vergonhas e secretas identificações. Esse efeito catártico da arte torna-se amplificado na sala escura do cinema, espaço diferenciado, com iluminação e sonorização especializadas para nos transportar para realidades que não são as nossas, mas que ali, por alguns momentos, podemos sentir as emoções e situações apresentadas pelos personagens fílmicos. 
O cinema, com suas imagens simbólicas, contém a riqueza do espírito humano, a linguagem afetiva de nossa corporeidade, amplificando emoções e sentimentos que nos fazem humanos em uma cultura de símbolos e significações. Essa perspectiva de abordagem do cinema pode contribuir para ampliar a visibilidade do corpo na Educação, fazendo-nos perceber outros ângulos, facetas, dimensões e matizes dos processos formativos do humano, através do corpo em movimento.

Em tempos de papiromania ${ }^{10}$ e verborragia acadêmicas, a vivência do exercício do olhar proposto por Merleau-Ponty, através da produção e apreciação de imagens fotográficas, cinematográficas, picturais, entre outras, contribui para repensar nossos modos de fazer pesquisa. No corpo, encontramos uma linha que é, ao mesmo tempo, de fuga, de resistência e de criação. Nessa perspectiva, a prática da investigação científica deixa de ser sobrevoo sobre o real, e passa a ser experiência dele, pois o habita. Alargar o pensamento, nesse sentido, passa a ser também arriscar-se nas aventuras do olhar, imiscuindo-se nas imagens, fundando ou forçando outros horizontes epistemológicos. Quando nos permitimos esse exercício, nos curamos, ao modo de uma catarse, da doença dos olhos à qual Pessoa associou o pensamento. Poderemos, então, aventurarmo-nos nos mapas do visível, fazendo de nossas pesquisas verdadeiras heterotopias ${ }^{11}$ dos sentidos, da visão, do pensar, dos modos de perguntar, enfim, diversas cartografias do ver.

\section{REFERÊNCIAS BIBLIOGRÁFICAS}

1. ABREU, O. A arte na filosofia de Deleuze. In: HADDOCK-LOBO, R. Os filósofos e a arte. Rio de Janeiro: Rocco, 2010.

2. AUMONT, J. et al. A estética do filme. Campinas: Papirus, 2007.

3. BAECQUE, A. Telas: o corpo no cinema. In: COURTINE, J-J. História do corpo: as mutações do olhar: o século XX. Petrópolis: Vozes, 2009.

4. CARBONE, Mauro. La chair des images: Merleau-Ponty entre peinture et cinéma. Paris: Vrin, 2011.

5. CHATEAU, Dominique. Philosophies du cinéma. Paris: Armand Colin, 2010.

6. FEITOSA, C. Explicando a Filosofia com arte. Rio de Janeiro: Ediouro, 2004.

7. IMBERT, Claude. Maurice Merleau-Ponty. Paris: Ministère des Affaires Étrangères, 2005.

8. JAY, Martin. Sartre, Merleau-Ponty, and the Search for a New Ontology of Sight. In: LEVIN, David Michael (org.). Modernity and the hegemony of the vision. University of California Press: Berkeley; Los Angeles; London, 1993.

9. MARTIN, Marcel. A linguagem cinematográfica. São Paulo: Brasiliense, 2007.

10. MERLEAU-PONTY, Maurice. A linguagem indireta e as vozes do silêncio. In: . O olho e o espírito seguido de $A$ linguagem indireta e as vozes do silêncio e $A$ dúvida de Cézanne. São Paulo: Cosac \& Naify, 2004.

\footnotetext{
${ }^{10}$ Devemos esta expressão ao Prof. Alfredo Veiga-Neto, que a utilizou na conferência de abertura do XI Colóquio sobre Questões Curriculares, no dia 18 de setembro de 2014, em Braga/Portugal. A conferência está disponível em: http://www.michelfoucault.com.br/files/XI\%20CQC\%20-\%20Curr\%C3\%ADculo\%20na\%20Contemporaneidade\%20\%2024set14[1].pdf.

${ }^{11}$ Expressão utilizada por Michel Foucault em texto homônimo. Cf. FOUCAULT, Michel. Heterotopies. In: Dits et Écrits II. Paris: Gallimard, 2001.
} 
11. Fenomenologia da Percepção. São Paulo: Martins Fontes, 2011.

12. . Le cinéma et la nouvelle psychologie. In: . Sens et non-sens. Paris: Gallimard, 1996.

13. La science et l'expérience de l'expression. In: . La prose du monde. Paris: Gallimard, 1969.

14. L'CEil et I'Esprit. Paris: Gallimard, 1964.

15. . Notes de cours 1959-1961. Paris: Gallimard, 1996.

16. O visível e o invisível. São Paulo: Perspectiva, 2012.

17. NÓBREGA, Terezinha Petrucia. Corpo, percepção e conhecimento em Merleau-Ponty, Estudos de Psicologia, 2008, 13(2), 141-148. Disponível na Internet: http://www.scielo.br/pdf/epsic/v13n2/06.pdf. Acesso em 29 de Out. 2014.

18. . Merleau-Ponty: o corpo como obra de arte, Princípios, Natal (RN), v.7, n. 8, p. 95-108, jan/dez 2000.

19. . Visibilidades do Corpo e da Cultura de Movimento Urbana (Relatório de Pesquisa). 2011.

20. O CORPO e a cidade. Direção: Terezinha Petrucia da Nóbrega. Produção: Buca Dantas. Natal, 2011. Documentário, 23'19". Disponível em: https://www.youtube.com/watch?v=oeMF1OqyUsQ. Acesso em Outubro de 2014.

21. PELLEJERO, Eduardo. Ver para crer: a arte de olhar e a filosofia das imagens, Princípios, Natal (RN), v. 20, n. 34, Jul/Dez 2013, p. 303-324.

22. PESSOA, Fernando. O guardador de rebanhos e outros poemas. São Paulo: Cultrix, 1997.

23. PINEL, Vincent. Vocabulaire technique du cinéma. Paris: Éditions Nathan, 1999.

24. VALÉRY, Paul. Le cimetière marin. Anagramme, 2007.

25. VERMELHO como o céu. Direção: Cristiano Bortone. Oriza Produzioni, 2006. 1 DVD (96 min), color. Título original: Rosso come il cielo.

26. XAVIER, I. Cinema: revelação e engano. In: NOVAES, A. O olhar. São Paulo: Companhia das Letras, 1997. 